OPEN ACCESS

Edited by:

Nicolas Stephane Merle, National Heart, Lung, and Blood Institute (NHLBI), United States

Reviewed by:

Magdalena Riedl Khursigara, Hospital for Sick Children, Canada

Bradley Patton Dixon,

Children's Hospital Colorado, United States

*Correspondence: Franck Pourcine franck.pourcine@ghsif.fr

Specialty section: This article was submitted to Molecular Innate Immunity, a section of the journal

Frontiers in Immunology

Received: 14 March 2021 Accepted: 27 May 2021 Published: 23 June 2021

Citation:

Boudhabhay I, Rabant M, Roumenina LT, Coupry L-M,

Poillerat $V$, Marchal A, Frémeaux-Bacchi V, El Karoui K, Monchi $M$ and Pourcine F (2021) Case Report: Adult Post-COVID-19 Multisystem Inflammatory Syndrome and Thrombotic Microangiopathy.

Front. Immunol. 12:680567. doi: 10.3389/fimmu.2021.680567

\section{Case Report: Adult Post-COVID-19 Multisystem Inflammatory Syndrome and Thrombotic Microangiopathy}

\author{
Idris Boudhabhay 1,2, Marion Rabant ${ }^{2}$, Lubka T. Roumenina ${ }^{3}$, Louis-Marie Coupry', \\ Victoria Poillerat ${ }^{3}$, Armance Marchal ${ }^{4}$, Véronique Frémeaux-Bacchi ${ }^{4}$, Khalil El Karoui ${ }^{5}$, \\ Mehran Monchi ${ }^{1}$ and Franck Pourcine ${ }^{1,6 *}$ \\ ${ }^{1}$ Groupe Hospitalier Sud lle de France, Service de Réanimation, Melun, France, ${ }^{2}$ Centre Hospitalo-Universitaire Necker, \\ Service d'Anatomie Pathologique, Paris, France, ${ }^{3}$ Centre de Recherche des Cordeliers, INSERM, Sorbonne Université, \\ Université de Paris, Paris, France, ${ }^{4}$ Hôpital Européen Georges Pompidou, Laboratoire d'Immunologie Biologique, Paris, \\ France, ${ }^{5}$ Centre Hospitalo-Universitaire Henri Mondor, Service de Néphrologie et Transplantation, Créteil, France, ${ }^{6}$ Groupe \\ Hospitalier Sud lle de France, Service de Néphrologie, Melun, France
}

Background: The coronavirus disease 2019 (COVID-19) pandemic has affected millions of people worldwide. A clinical series of Kawasaki-like multisystem inflammatory syndrome (MIS), occurring after SARS-CoV-2 infection, have been described in children (MIS-C) and adults (MIS-A), but the pathophysiology remains unknown.

Case Presentation: We describe a case of post-COVID-19 MIS-A in a 46-year-old man with biopsy-proven renal thrombotic microangiopathy (TMA). Specific complement inhibition with eculizumab was initiated promptly and led to a dramatic improvement of renal function.

Conclusion: Our case suggests that that TMA could play a central role in the pathophysiology of post-COVID-19 MIS-A, making complement blockers an interesting therapeutic option.

Keywords: thrombotic microangiopathy, multisystem inflammatory syndrome, COVID-19, complement system, eculizumab, case report

\section{INTRODUCTION}

The coronavirus disease 2019 (COVID-19) pandemic caused by SARS-CoV-2 has affected millions of people worldwide. In adults, COVID-19 is typically characterised by severe interstitial pneumonia and hyperactivation of the inflammatory cascade (1). There is growing evidence that COVID-19 affects the endothelial system, leading to endothelial dysfunction characterised by a pro-inflammatory and procoagulative state (2-5). Clinical series of Kawasaki-like multisystem inflammatory syndrome (MIS), occurring after viral clearance, have been described in children (MIS-C) (6-9). Recently, similar case

\footnotetext{
Abbreviations: aHUS, atypical haemolytic uremic syndrome; AKI, acute kidney injury; BMI, body mass index; CFB, Complement factor B; CFH, Complement factor H; CFI, Complement factor I; MCP, Membrane Cofactor Protein; CRP, C-reactive protein; hsTroponin, high-sensitivity troponin; MAC, membrane attack complex; MIS-C, multisystem inflammatory syndrome in children; MIS-A, multisystem inflammatory syndrome in adults; PCR, polymerase chain reaction; RRT, renal replacement therapy; sCr, serum creatinine; sC5b-9, soluble C5b-9; TMA, thrombotic microangiopathy; THBD, Thrombomodulin.
} 
series of MIS were described in adults (MIS-A) (10-15). However, the pathophysiology of MIS remains unknown. We report a case of MIS-A with biopsy-proven thrombotic microangiopathy (TMA) successfully treated with eculizumab.

\section{CASE PRESENTATION}

A 46-year-old patient of West African ancestry was admitted to our hospital for hypertensive emergency $(189 / 123 \mathrm{mmHg})$ and fever. He had a personal history of arterial hypertension and obesity $\left(\right.$ BMI $\left.=36 \mathrm{~kg} / \mathrm{m}^{2}\right)$ and family history of arterial hypertension. No previous COVID-19 symptoms were reported, and the patient did not take any prescribed or over-the-counter medications. Physical examination was normal. SARS-CoV-2 PCR of nasopharyngeal swab was negative (repeated twice), but COVID-19 serology was positive for IgG (80 UA/mL, positive if $>12 \mathrm{UA} / \mathrm{mL}$, Immunoassay YHLO iFlash 1800) and negative for IgM. Thoracoabdominopelvic CT scan was unremarkable. First investigations revealed an inflammatory state, anaemia, thrombocytopenia and acute kidney injury (AKI). The serum creatinine (sCr) level was $169 \mu \mathrm{mol} / \mathrm{L}$ and associated with $1 \mathrm{~g}$ per day proteinuria, aseptic pyuria, no haematuria and low natriuresis (<20 mmol/L). C-reactive protein (CRP) level was $312 \mathrm{mg} / \mathrm{L}$ and neutrophil count was $18.7 \mathrm{~g} / \mathrm{L}$ (Table 1). On day 4, the patient presented with evanescent facial erythema and developed acute myocardial dysfunction with reduced left ventricular ejection fraction (40\%), pericardial effusion and elevation of highsensitivity troponin (hsTroponin). Taking into account the frequency of vascular thromboses related to COVID-19, therapeutic anticoagulation with heparin was started. On day 5 , neurological impairment appeared with coma, leading to intubation and mechanical ventilation. Cerebrospinal fluid analysis was unremarkable. Abnormal supratentorial periventricular MRI signals responsible for a restriction of the diffusion testified to acute vasculitis. No immunosuppressive treatment was introduced because of concomitant tracheal aspiration positive for Enterobacter aerogenes, which was treated with trimethoprim-sulfamethoxazole. On day 7, myocardial and renal function worsened $(\mathrm{sCr} 660 \mu \mathrm{mol} / \mathrm{L})$, requiring initiation of dobutamine and intermittent renal replacement therapy (RRT). A kidney biopsy was performed. Light microscopy revealed typical lesions of TMA, including fibrin thrombi within glomeruli and myxoid intimal alterations of arterioles and small-to-medium sized renal arteries. The remaining glomeruli were normal without hypercellularity. A significant interstitial infiltrate, mainly composed of neutrophils, was responsible for severe tubulitis and moderate acute tubular necrosis (Figure 1A). Immunofluorescence study showed isolated mesangial complement C3c-positive deposits without evidence for IgG, IgA, IgM, C1q or C4d deposits (Figure 1B). Immunochemistry study showed C5b-9 deposits at the same localisation (Figure 1C). Immunological work-up is shown in Table 2. ADAMTS13 activity was moderately decreased but did not reach the cut-off for a diagnosis of thrombotic thrombocytopenic purpura. Complement work-up evaluation found an elevated soluble C5b-9 (sC5b-9) with low C4 and normal C3 levels in the serum (Table 2). Cryoglobulinemia was negative. All coding sequences of $\mathrm{CFH}$, $C F I, M C P, C 3, C F B$ and THBD genes were analysed by nextgeneration sequencing. We defined a variant as rare when its minor allele frequency was below $1 \%$ in the general population. No rare variants were detected in the six complement genes implicated in atypical haemolytic uremic syndrome (aHUS).

On day 8, specific complement inhibition with eculizumab (900 mg) was initiated. Three days later, cardiac function and neurological impairment improved, urine output increased, and blood creatinine decreased, allowing the withdrawal of dobutamine, RRT and mechanical ventilation (Table 1). On day 15 , the patient received a second and last dose of eculizumab (900 $\mathrm{mg}$ ). On day 30, the patient was discharged from the hospital, with a sCr $109 \mu \mathrm{mol} / \mathrm{L}$ and cardiac MRI showing no pericardial effusion, no sequelae of segmental hypokinesia and a left ventricular ejection fraction of $50 \%$. Six months later, the patient resumed normal activities of daily living. Left ventricular function has normalised, despite persistent arterial hypertension. $\mathrm{sCr}$ is 82 $\mu \mathrm{mol} / \mathrm{L}$, without significant albuminuria (Tables 1 and 2).

\section{DISCUSSION AND CONCLUSION}

We describe the first case of post-COVID19 MIS-A associated with renal TMA successfully treated with eculizumab.

In this case, the IgG-positive serology, negative PCR swab and the absence of pulmonary involvement demonstrate the postinfectious nature of this syndrome, occurring after viral clearance.

Kidney involvement is frequent in COVID-19, as more than $40 \%$ of cases have abnormal proteinuria at hospital admission $(16,17)$. Scarce histological data are available, showing in most cases ATN, collapsing glomerulopathy or TMA in patients with acute COVID-19 infection (18-22). AKI is also common during MIS-C, ranging from $10 \%$ to $60 \%$ of the cases $(6,23,24)$ while it was described in four adults in a case series of 20 MIS-A with cardiac involvement (12). Currently, the pathogenesis of AKI in MIS is thought to be mainly related to cytokine-mediated hypotension and cardiac dysfunction, leading to renal hypoperfusion (25).

Our case describes the first kidney biopsy performed in a patient with MIS-A. Scarce histological data are available on this syndrome. A first report showed intraepithelial collections of neutrophils with necrotic keratinocytes in skin biopsy (10). Likewise, in a fatal case of MIS-A, cardiac vasculitis composed of numerous neutrophils and CD4+ T cells was described (14). Similarly, in our case, renal biopsy revealed an aggressive interstitial infiltrate, mainly composed of neutrophils together with TMA.

TMA refers to pathological features of microvascular injury, including thrombi of platelets and fibrin in capillaries and arterioles $(26,27)$. These lesions are usually associated with peripheral thrombocytopenia and mechanical haemolytic anaemia, although some of these biological markers may be absent $(27,28)$. In our patient, the absence of a decreased haptoglobin level could be explained by the intensity of the inflammatory syndrome and predominant intrarenal TMA. 
Days from hospital admission

\begin{tabular}{|c|c|c|c|c|c|c|c|c|c|c|c|c|c|c|c|c|c|c|c|c|c|c|}
\hline Finding & & 1 & 2 & 3 & 4 & 5 & 6 & 7 & $8^{*}$ & 9 & 10 & 11 & 12 & 13 & 14 & $15^{\star}$ & 16 & 17 & 18 & 19 & 30 & 182 \\
\hline \multicolumn{23}{|l|}{ Clinical } \\
\hline Respiratory status & & SB & SB & SB & $\mathrm{O} 2$ & MV & MV & MV & MV & MV & MV & MV & MV & SB & SB & SB & SB & SB & SB & SB & SB & SB \\
\hline Dobutamine (gamma/kg/min) & & - & - & - & - & - & - & 5.75 & 10 & 10 & 10 & 5 & - & - & - & - & - & - & - & - & - & - \\
\hline Urine output (L/day) & & - & - & - & 0.3 & 0.3 & 0.5 & 0.7 & 0.8 & 0.9 & 3 & 7.8 & 6.9 & 7.4 & 5.2 & 6.3 & 4.2 & 2.8 & 2.7 & 2.2 & 1.5 & - \\
\hline Temperature $\left({ }^{\circ} \mathrm{C}\right)$ & & 40.7 & 40.6 & 40 & 40.2 & 39.1 & 38.7 & 38.4 & 37.3 & 38.1 & 36.3 & 36.8 & 36.2 & 36.1 & 36.2 & 36 & 35.7 & 34.7 & 35.7 & 36 & 36 & 37 \\
\hline Laboratory & Normal values & & & & & & & & & & & & & & & & & & & & & \\
\hline Creatinine $(\mu \mathrm{mol} / \mathrm{L})$ & [59-104] & 169 & 225 & 348 & 536 & 627 & 666 & RRT & 691 & RRT & 441 & 395 & 324 & 256 & 208 & 167 & 147 & 130 & 151 & 129 & 109 & 82 \\
\hline CRP (mg/L) & {$[<5]$} & 312 & 469 & 528 & 621 & 551 & 462 & 319 & 292 & 213 & 153 & 87 & 58 & 45 & 32.9 & 25 & 19 & 12.9 & 11.4 & 8.8 & 3 & 3.7 \\
\hline Leucocyte count (G/L) & {$[4-10]$} & 18.7 & 15.7 & 20 & 25 & 25.1 & 26.8 & 25.7 & 26.7 & 19.9 & 17 & 12.3 & 11.9 & 10.3 & 9.3 & 7.7 & 8 & 5.5 & 4.4 & 3.3 & 5.7 & 8.6 \\
\hline Haemoglobin level (g/dL) & [13-16.7] & 12.3 & 9.8 & 8.3 & 7.5 & 7.1 & 6.6 & 7.3 & 7 & 6.2 & 6.7 & 7.6 & 7.8 & 8.7 & 8.7 & 9.2 & 9.7 & 8.8 & 9.7 & 9.3 & 12.6 & 13.3 \\
\hline Platelet count (G/L) & [150-450] & 98 & 90 & 97 & 288 & 392 & 450 & 392 & 339 & 260 & 261 & 267 & 267 & 311 & 315 & 330 & 347 & 304 & 326 & 300 & 217 & 389 \\
\hline LDH (UI/L) & [135-225] & 461 & 432 & 473 & - & - & - & 491 & 636 & 435 & 449 & 413 & 386 & - & 372 & 358 & 333 & 280 & 288 & 243 & - & - \\
\hline hsTroponin (ng/L) & {$[<14]$} & 25 & 74 & - & 1006 & 1700 & 2791 & 2464 & 1669 & - & 1048 & 628 & 481 & 294 & 214 & 130 & 98.7 & - & 120 & 140 & 28 & 21.6 \\
\hline Haptoglobin $(g / L)$ & [0.3-2] & - & - & - & 2.91 & 2.91 & - & - & - & - & - & - & - & - & - & - & - & 2.67 & 2.41 & 2.71 & - & - \\
\hline Ferritin $(\mu \mathrm{g} / \mathrm{L})$ & [30-400] & - & 3206 & - & - & 3538 & - & - & - & - & - & - & - & - & - & - & - & - & - & - & - & - \\
\hline Schistocytes (\%) & $<1 \%$ & - & - & $<1$ & $<1$ & - & - & - & - & - & - & - & - & - & - & - & - & - & - & - & $<1$ & - \\
\hline UPCR $(\mathrm{mg} / \mathrm{g})$ & $<300$ & 996 & - & - & - & - & 686 & - & - & - & - & - & - & - & - & - & - & - & - & - & 90 & 90 \\
\hline Others & \multicolumn{22}{|c|}{ HBV, HCV and HIV 1 serologies: negatives; glycosylated ferritin $12 \%(N>20 \%)$; } \\
\hline
\end{tabular}

HBV, hepatitis B virus; HCV, hepatitis C virus; HIV, human immunodeficiency Virus; hsTroponin, High-sensitive Troponin; LDH, Lactate dehydrogenase; MV, mechanical ventilation; O2, oxygen therapy; RRT, renal replacement therapy; $S B$, spontaneous breathing; UPCR, urine protein creatinine ratio.

*eculizumab 900mg.

Bold data on the first line correspond to the days from patient's hospital admission. 
A

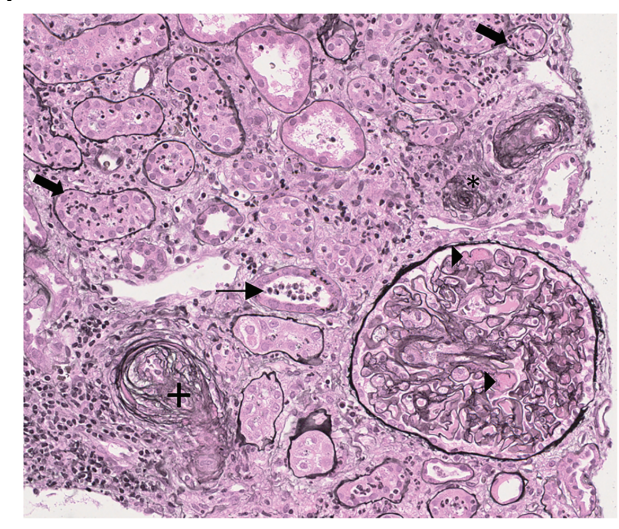

C

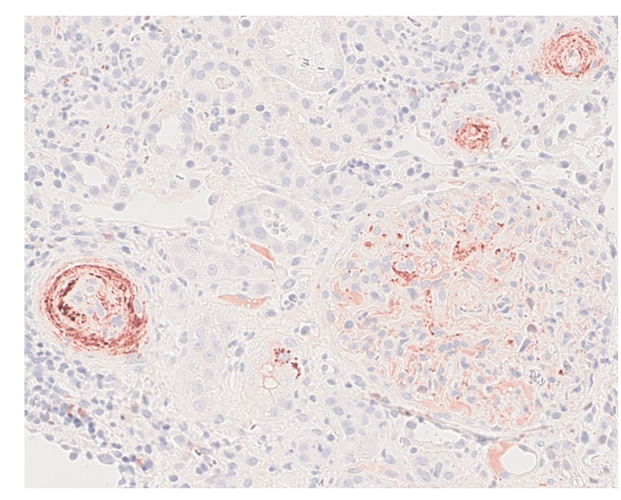

B

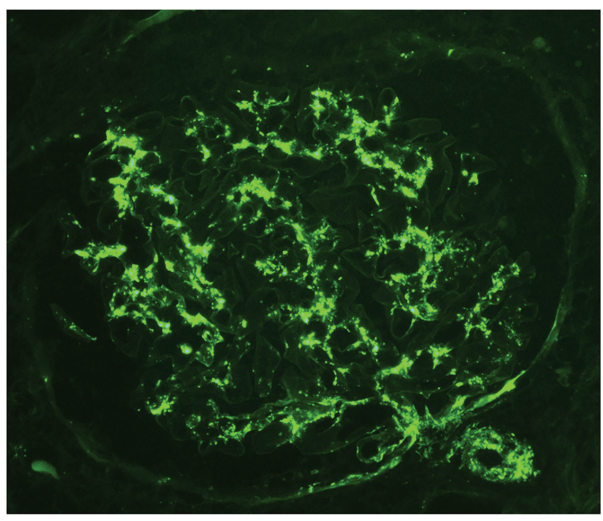

FIGURE 1 | Kidney biopsy findings. (A) Light microscopy analysis: Fibrin within glomerular capillary loops (black triangle). Small inter-lobular artery with intimal mucoid alterations and endothelial cells swelling (+). Arteriolar occlusion (*). Polymorphonuclear infiltration with tubulitis (thick arrows) and granular casts (thin arrow) (Jones methanamine silver staining, x200). (B) Immunofluorescence stucy showing predominant mesangial and sub-endothelial C3 deposits in glumeruli and in glomerular arteriole. (Anti-C3c fluorescein isothiocyanate-conjugate $\times 400$ ). (C) Immunochemistry study showing positive C5b-9 staining in arterioles, inter-lobular artery and glomeruli within the mesangium (Mouse IgG, B7 antineoepitope, $\left.{ }^{1} \mathrm{x} 40\right) .{ }^{1}$ Kindly provided by Prof. P. Morgan (Cardiff Intitute of Infection\&Immunity, UK).

TABLE 2 | Immunological work-up.

\begin{tabular}{lccc}
\hline Laboratory & Normal values & Day 1 & Day 182 \\
\hline ADAMTS-13 activity (\%) & $50-150$ & 26 & - \\
CH $\mathbf{5 0}$ (\%) & $70-130$ & 64 & 106 \\
C3 (mg/L) & $660-1250$ & 1030 & 1360 \\
C4 (mg/L) & $93-380$ & 69 & 314 \\
C1q (mg/L) & $125-225$ & 227 & - \\
Factor H (\%) & $65-140$ & 93 & 116 \\
Factor I (\%) & $70-130$ & 122 & 134 \\
sC5b9 (ng/mL) & $<420$ & 469 & - \\
Properdin (mg/L) & $12-40$ & 38 & - \\
C1 inhibitor antigen (mg/L) & $170-540$ & 357 & - \\
C1 inhibitor function (\%) & $70-130$ & $>125$ & - \\
Anti-Factor H antibodies & - & negative & negative \\
Antinuclear antibodies & - & $1 / 160$ & - \\
Anti-DNA antibodies & - & $n e g a t i v e$ & - \\
Cryoglobulinemia & - & negative & - \\
Anti-cardiolipin antibodies & - & negative & - \\
Anti-B2GP1 antibodies & - & negative & - \\
Lupus anticoagulant & - & negative & - \\
\hline
\end{tabular}

ADAMTS13, a disintegrin and metalloprotease with thrombospondin type I repeats-13; sC5b9, soluble C5b-9 plasmatic level; DNA, desoxyribonucleic acid; B2GP1, beta 2 glycoprotein 1.
Diorio et al. recently proposed criteria for clinical TMA associated with MIS-C, including: schistocytes on blood smear, anaemia, elevated $\mathrm{LDH}$, new thrombocytopenia, anaemia, proteinuria, hypertension and elevated sC5b9 (29). Our patient fulfilled five out of seven of the criteria, thus meeting their definition. aHUS is a form of TMA with predominant kidney involvement. The pathophysiology of aHUS involves multiple hits (30), but complement activation has a crucial role in this syndrome. Genetically determined or acquired dysregulation of the complement alternative pathway (CAP) has been found in up to $70 \%$ of patients with aHUS (27). Genetic screening was negative in our patient. Although we cannot exclude an unknown variant, it is likely that our patient presented with MIS-A complicated with TMA, rather than aHUS unmasked by SARS-CoV-2 infection.

The complement system (CS) seems to play a pivotal role in the pathophysiology of COVID-19, as few series have reported TMA injury in lungs and skin with sustained activation of CAP and lectin pathway during COVID-19 disease (31-33). Moreover, mice lacking complement component C3, display less 
severe respiratory failure and inflammatory syndrome after SARS-Cov infection (34). Likewise, complement overactivation likely contributes to the renal injury during the course of COVID-19 infection, since a few studies have showed complement deposits in vascular beds and tubules (35). In this case, low serum C4 with normal C3 and mildly elevated sC5b-9 is suggestive of classical and/or lectin complement pathways activation. As MIS-A is a post-infectious immune-mediated phenomenon, anti-SARS-CoV-2 immune complexes could drive complement activation. However, Diorio et al. found no correlation between SARS-CoV-2 antibodies and sC5b-9 elevations (29). Moreover, in our case, histopathological analysis revealed evidence of TMA together with $\mathrm{C} 3 \mathrm{c}$ deposits but without $\mathrm{C} 4 \mathrm{~d}$ or immunoglobulin deposits, which suggestive of alternative complement pathway activation. Lectin pathway triggering, though, cannot be excluded, since it can occur in a C4-bypass pathway and MASP-2 has been suggested to play a key role in the disease process of COVID-19 $(33,36,37)$. In our patient, sC5b-9 levels were elevated and C5b-9 staining was positive in kidney biopsy, which is indicative of C5 cleavage by C5 convertase, as described in patients with COVID-19 (38). Likewise, Diorio et al. studied 50 hospitalised paediatric patients with acute SARS-CoV-2 infection ( $\mathrm{n}=21$ minimal COVID-19; $\mathrm{n}=11$ severe COVID-19 and $\mathrm{n}=18$ MIS-C) (29); 11 of 18 patients with MIS-C met clinical criteria for TMA. The median sC5b-9 was higher in the patients meeting TMA criteria and associated with AKI. None of the 18 patients needed RRT and no kidney biopsy was performed. Noteworthy, sC5b-9 was also elevated in patients with minimal COVID-19 disease. Eculizumab is a monoclonal anti-C5 antibody that blocks the formation of the membrane attack complex on the surface of endothelial cells and has revolutionised the prognosis of aHUS $(39,40)$. Small case series have suggested the potential benefits of eculizumab in COVID-19 (41-43). However, no randomized clinical trial has been published to date (32). In our patient, kidney function improved after eculizumab. However, fever, thrombocytopenia and troponin levels were already improving before using any complement blockade. Six months later and after only two courses of eculizumab, our patient's kidney function has normalised without albuminuria. Likewise, in the case series of MIS-C with TMA published by Diorio et al., all the children recovered (29). Therefore, we cannot exclude that improvement was due to the natural course of the disease rather than to eculizumab, as described in HUS caused by an infection from

\section{REFERENCES}

1. Guan WJ, Ni ZY, Hu Y, Liang WH, Ou CQ, He JX, et al. Clinical Characteristics of Coronavirus Disease 2019 in China. N Engl J Med (2020) 382:1708-20. doi: 10.1056/NEJMoa2002032

2. Varga Z, Flammer AJ, Steiger P, Haberecker M, Andermatt R, Zinkernagel SA, et al. Endothelial Cell Infection and Endotheliitis in COVID-19. Lancet (2020) 395:1417-8. doi: 10.1016/S0140-6736(20)30937-5

3. Gupta A, Madhavan MV, Sehgal K, Nair N, Mahajan S, Sehrawat TS, et al. Extrapulmonary Manifestations of COVID-19. Nat Med (2020) 26:1017-32. doi: 10.1038/s41591-020-0968-3

4. Libby P, Lüscher T. Covid-19 Is, in the End, An Endothelial Disease. Eur Heart J (2020) 41:3038-44. doi: 10.1093/eurheartj/ehaa623 shiga toxin-producing Escherichia coli (STEC) (27). Complement blockers have never been tested in patients with MIS, except in a 14-year-old child with features of both acute COVID-19 infection and MIS-C, who developed TMA (44). In this case, a kidney biopsy could not be performed, but AKI resolved on eculizumab, as in our patient.

In conclusion, our case suggests that TMA could play a central role in the pathophysiology of post COVID-19 MIS, making complement blockers an interesting therapeutic option.

\section{DATA AVAILABILITY STATEMENT}

The original contributions presented in the study are included in the article/supplementary material. Further inquiries can be directed to the corresponding author.

\section{ETHICS STATEMENT}

Written informed consent was obtained from the individual(s) for the publication of any potentially identifiable images or data included in this article.

\section{AUTHOR CONTRIBUTIONS}

IB and FP wrote the manuscript. MR is the pathologist who made the diagnosis and took the photographs in Figure 1. KE-K, L-MC, LR, and MM participated in proofreading and collection of data. AM performed the biochemical analysis of the complement pathway. VP performed C5b-9 staining on the kidney biopsy. VF-B performed genetic analysis. FP is the corresponding author. All authors contributed to the article and approved the submitted version.

\section{ACKNOWLEDGMENTS}

We thank all the team at the Melun Intensive Care Unit who were involved in the care of patients during the COVID19 pandemic.

5. Huertas A, Montani D, Savale L, Pichon J, Tu L, Parent F, et al. Endothelial Cell Dysfunction: A Major Player in SARS-CoV-2 Infection (COVID-19)? Eur Respir J (2020) 56(1):2001634. doi: 10.1183/13993003.01634-2020

6. Basalely A, Gurusinghe S, Schneider J, Shah SS, Siegel LB, Pollack G, et al. Acute Kidney Injury in Pediatric Patients Hospitalized With Acute COVID19 and Multisystem Inflammatory Syndrome in Children Associated With COVID-19. Kidney Int (2021)S0085-2538(21):00268-4. doi: 10.1016/ j.kint.2021.02.026

7. Feldstein LR, Rose EB, Horwitz SM, Collins JP, Newhams MM, Son MBF, et al. Multisystem Inflammatory Syndrome in U.S. Children and Adolescents. N Engl J Med (2020) 383:334-46. doi: 10.1056/NEJMoa2021680

8. Chiotos K, Bassiri H, Behrens EM, Blatz AM, Chang J, Diorio C, et al. Multisystem Inflammatory Syndrome in Children During the Coronavirus 
2019 Pandemic: A Case Series. J Pediatr Infect Dis Soc (2020) 9:393-8. doi: 10.1093/jpids/piaa069

9. Ahmed M, Advani S, Moreira A, Zoretic S, Martinez J, Chorath K, et al. Multisystem Inflammatory Syndrome in Children: A Systematic Review. EClinicalMedicine (2020) 26:100527. doi: 10.1016/j.eclinm.2020.100527

10. Shaigany S, Gnirke M, Guttmann A, Chong H, Meehan S, Raabe V, et al. An Adult With Kawasaki-Like Multisystem Inflammatory Syndrome Associated With COVID-19. Lancet (2020) 396(10246):e8-e10. doi: 10.1016/S0140-6736 (20)31526-9

11. Sokolovsky S, Soni P, Hoffman T, Kahn P, Scheers-Masters J. Covid-19 Associated Kawasaki-Like Multisystem Inflammatory Disease in an Adult. Am J Emerg Med (2021) 39:253.e251-3.e252. doi: 10.1016/j.ajem.2020.06.053

12. Hékimian G, Kerneis M, Zeitouni M, Cohen-Aubart F, Chommeloux J, Bréchot N, et al. Coronavirus Disease 2019 Acute Myocarditis and Multisystem Inflammatory Syndrome in Adult Intensive and Cardiac Care Units. Chest (2021) 159:657-62. doi: 10.1016/j.chest.2020.08.2099

13. Chau VQ, Giustino G, Mahmood K, Oliveros E, Neibart E, Oloomi M, et al. Cardiogenic Shock and Hyperinflammatory Syndrome in Young Males With Covid-19. Circ Heart Fail (2020) 13:e007485. doi: 10.1161/ CIRCHEARTFAILURE. 120.007485

14. Fox SE, Lameira FS, Rinker EB, Vander Heide RS. Cardiac Endotheliitis and Multisystem Inflammatory Syndrome After Covid-19. Ann Intern Med (2020) 173:1025-7. doi: 10.7326/L20-0882

15. Newton-Cheh C, Zlotoff DA, Hung J, Rupasov A, Crowley JC, Funamoto M. Case 24-2020: A 44-Year-Old Woman With Chest Pain, Dyspnea, and Shock. N Engl J Med (2020) 383:475-84. doi: 10.1056/NEJMcpc2004975

16. Cheng Y, Luo R, Wang K, Wang Z, Dong L, Li J, et al. Kidney Disease Is Associated With In-Hospital Death of Patients With COVID-19. Kidney Int (2020) 97:829-38. doi: 10.1016/j.kint.2020.03.005

17. Batlle D, Soler MJ, Sparks MA, Hiremath S, South AM, Welling PA, et al. Acute Kidney Injury in COVID-19: Emerging Evidence of a Distinct Pathophysiology. J Am Soc Nephrol (2020) 31:1380-3. doi: 10.1681/ASN.2020040419

18. Su H, Yang M, Wan C, Yi LX, Tang F, Zhu HY, et al. Renal Histopathological Analysis of 26 Postmortem Findings of Patients With COVID-19 in China. Kidney Int (2020) 98(1):219-27. doi: 10.1016/j.kint.2020.04.003

19. Larsen CP, Bourne TD, Wilson JD, Saqqa O and Sharshir MA. Collapsing Glomerulopathy in a Patient With Coronavirus Disease 2019 (Covid-19). Kidney Int Rep (2020) 5(6):935-9. doi: 10.1016/j.ekir.2020.04.002

20. Ferlicot S, Jamme M, Gaillard F, Oniszczuk J, Couturier A, May O, et al. The Spectrum of Kidney Biopsies in Hospitalized Patients With COVID-19, Acute Kidney Injury, and/or Proteinuria. Nephrol Dial Transplant (2021) 12: gfab042. doi: 10.1093/ndt/gfab042

21. Kudose S, Batal I, Santoriello D, Xu K, Barasch J, Peleg Y, et al. Kidney Biopsy Findings in Patients With COVID-19. J Am Soc Nephrol (2020) 31:1959-68. doi: 10.1681/ASN.2020060802

22. Jhaveri KD, Meir LR, Flores Chang BS, Parikh R, Wanchoo R, Barilla-LaBarca ML, et al. Thrombotic Microangiopathy in a Patient With COVID-19. Kidney Int (2020) 98(2):509-12. doi: 10.1016/j.kint.2020.05.025

23. González-Dambrauskas S, Vásquez-Hoyos P, Camporesi A, Díaz-Rubio F, Piñeres-Olave BE, Fernández-Sarmiento J, et al. Pediatric Critical Care and COVID-19. Pediatrics (2020) 146(3):e20201766. doi: 10.1542/peds.2020-1766

24. Godfred-Cato S, Bryant B, Leung J, Oster ME, Conklin L, Abrams J, et al. Covid-19-Associated Multisystem Inflammatory Syndrome in Children United States, March-July 2020. MMWR Morbid Mortal Wkly Rep (2020) 69:1074-80. doi: 10.15585/mmwr.mm6932e2

25. Whittaker E, Bamford A, Kenny J, Kaforou M, Jones CE, Shah P, et al. Clinical Characteristics of 58 Children With a Pediatric Inflammatory Multisystem Syndrome Temporally Associated With SARS-Cov-2. JAMA (2020) 324:25969. doi: 10.1001/jama.2020.10369

26. George JN, Nester CM. Syndromes of Thrombotic Microangiopathy. N Engl J Med (2014) 371:654-66. doi: 10.1056/NEJMra1312353

27. Fakhouri F, Zuber J. Fremeaux-Bacchi V and Loirat C.Haemolytic Uraemic Syndrome. Lancet (Lond Engl) (2017) 390:681-96. doi: 10.1016/S0140-6736 (17)30062-4

28. Sellier-Leclerc AL, Fremeaux-Bacchi V, Dragon-Durey MA, Macher MA, Niaudet P, Guest G, et al. Differential Impact of Complement Mutations on Clinical Characteristics in Atypical Hemolytic Uremic Syndrome. J Am Soc Nephrol: JASN (2007) 18:2392-400. doi: 10.1681/ASN.2006080811
29. Diorio C, McNerney KO, Lambert M, Paessler M, Anderson EM, Henrickson SE, et al. Evidence of Thrombotic Microangiopathy in Children With SARSCoV-2 Across the Spectrum of Clinical Presentations. Blood Adv (2020) 4:6051-63. doi: 10.1182/bloodadvances.2020003471

30. Frimat M, Boudhabhay I, Roumenina LT. Hemolysis Derived Products Toxicity and Endothelium: Model of the Second Hit. Toxins (Basel) (2019) 11(11):660. doi: 10.3390/toxins11110660

31. Magro C, Mulvey JJ, Berlin D, Nuovo G, Salvatore S, Harp J, et al. Complement Associated Microvascular Injury and Thrombosis in the Pathogenesis of Severe COVID-19 Infection: A Report of Five Cases. Transl Res (2020) 220:1-13. doi: 10.1016/j.trsl.2020.04.007

32. Java A, Apicelli AJ, Liszewski MK, Coler-Reilly A, Atkinson JP, Kim AH, et al. The Complement System in COVID-19: Friend and Foe? JCI Insight (2020) 5 (15):e140711. doi: 10.1172/jci.insight.140711

33. Rambaldi A, Gritti G, Micò MC, Frigeni M, Borleri G, Salvi A, et al. Endothelial Injury and Thrombotic Microangiopathy in COVID-19: Treatment With the Lectin-Pathway Inhibitor Narsoplimab. Immunobiology (2020) 225:152001. doi: 10.1016/j.imbio.2020.152001

34. Gralinski LE, Sheahan TP, Morrison TE, Menachery VD, Jensen K, Leist SR, et al. Complement Activation Contributes to Severe Acute Respiratory Syndrome Coronavirus Pathogenesis. mBio (2018) 9(5):e01753-18. doi: 10.1128/mBio.01753-18

35. Pfister F, Vonbrunn E, Ries T, Jäck HM, Überla K, Lochnit G, et al. Complement Activation in Kidneys of Patients With Covid-19. Front Immunol (2020) 11:594849. doi: 10.3389/fimmu.2020.594849

36. Farrar CA, Tran D, Li K, Wu W, Peng Q, Schwaeble W, et al. Collectin-11 Detects Stress-Induced L-fucose Pattern to Trigger Renal Epithelial Injury. J Clin Invest (2016) 126:1911-25. doi: 10.1172/JCI83000

37. Boudhabhay I, Poillerat V, Grunenwald A, Torset C, Leon J, Daugan MV, et al. Complement Activation Is a Crucial Driver of Acute Kidney Injury in Rhabdomyolysis. Kidney Int (2021) 99:581-97. doi: 10.1016/j.kint.2020.09.033

38. Cugno M, Meroni PL, Gualtierotti R, Griffini S, Grovetti E, Torri A, et al. Complement Activation in Patients With COVID-19: A Novel Therapeutic Target. J Allergy Clin Immunol (2020) 146(1):215-7. doi: 10.1016/j.jaci. 2020.05.006

39. Legendre CM, Licht C, Muus P, Greenbaum LA, Babu S, Bedrosian C, et al. Terminal Complement Inhibitor Eculizumab in Atypical Hemolytic-Uremic Syndrome. N Engl J Med (2013) 368:2169-81. doi: 10.1056/NEJMoa1208981

40. Zuber J, Frimat M, Caillard S, Kamar N, Gatault P, Petitprez F, et al. Use of Highly Individualized Complement Blockade Has Revolutionized Clinical Outcomes After Kidney Transplantation and Renal Epidemiology of Atypical Hemolytic Uremic Syndrome. J Am Soc Nephrol (2019) 30:2449-63. doi: 10.1681/ASN.2019040331

41. Diurno F, Numis FG, Porta G, Cirillo F, Maddaluno S, Ragozzino A, et al. Eculizumab Treatment in Patients With COVID-19: Preliminary Results From Real Life ASL Napoli 2 Nord Experience. Eur Rev Med Pharmacol Sci (2020) 24:4040-7. doi: 10.26355/eurrev_202004_20875

42. Peffault de Latour R, Bergeron A, Lengline E, Dupont T, Marchal A, Galicier L, et al. Complement C5 Inhibition in Patients With COVID-19 - A Promising Target? Haematologica (2020) 105:2847-50. doi: 10.3324/haematol.2020.260117 43. Annane D, Heming N, Grimaldi-Bensouda L, Frémeaux-Bacchi V, Vigan M, Roux AL, et al. Eculizumab as an Emergency Treatment for Adult Patients With Severe COVID-19 in the Intensive Care Unit: A Proof-of-Concept Study. EClinicalMedicine (2020) 28:100590. doi: 10.1016/j.eclinm.2020.100590

44. Mahajan R, Lipton M, Broglie L, Jain NG, Uy NS. Eculizumab Treatment for Renal Failure in a Pediatric Patient With COVID-19. J Nephrol (2020) 33:1373-6. doi: 10.1007/s40620-020-00858-2

Conflict of Interest: The authors declare that the research was conducted in the absence of any commercial or financial relationships that could be construed as a potential conflict of interest.

Copyright (c) 2021 Boudhabhay, Rabant, Roumenina, Coupry, Poillerat, Marchal, Frémeaux-Bacchi, El Karoui, Monchi and Pourcine. This is an open-access article distributed under the terms of the Creative Commons Attribution License (CC BY). The use, distribution or reproduction in other forums is permitted, provided the original author(s) and the copyright owner(s) are credited and that the original publication in this journal is cited, in accordance with accepted academic practice. No use, distribution or reproduction is permitted which does not comply with these terms. 